\title{
Dental Visits and Predictors of Regular Attendance Among Female Schoolchildren in Dammam, Saudi Arabia
}

This article was published in the following Dove Press journal: Clinical, Cosmetic and Investigational Dentistry

\author{
Muhanad Alhareky \\ Muhammad Ashraf Nazir iD \\ Department of Preventive Dental \\ Sciences, College of Dentistry, Imam \\ Abdulrahman Bin Faisal University, \\ Dammam, Saudi Arabia
}

Purpose: Regular dental visits are important for the maintenance of optimal oral health and improved quality of life. The purpose of the study was to evaluate patterns of dental visits and factors associated with routine dental attendance among female schoolchildren in Dammam, Saudi Arabia.

Patients and Methods: This cross-sectional study was performed on 449 female primary schoolchildren (6-11 years old) in Dammam, Saudi Arabia. The study included clinical examination for decay in the first permanent molars in children and questionnaire administration among their parents. The World Health Organization's oral health questionnaire was used to collect data about children's dental visits, oral hygiene behaviors, dental problems, and dietary practices. Bivariate and multivariate analyses were performed to evaluate factors associated with routine dental visits.

Results: Most children (64.1\%) visited the dentist during the past one year, $22.1 \%$ performed no dental visit during the past one year, and $8.3 \%$ never visited the dentist. Among children who visited the dentist, the pain was the most common reason for dental visits (39.10\%, $\mathrm{N}=170)$, followed by routine dental check-ups $(18.60 \%, \mathrm{~N}=81)$. In bivariate analysis, education of parents, family income, daily tooth brushing, no decay in the first permanent molar, no toothache, no consumption of soft drinks, biscuits, cakes, and cream were significantly associated with routine dental attendance $(\mathrm{P}<0.05)$. However, the final logistic regression model showed that university education of mothers ( $\mathrm{OR} 2.52, \mathrm{P}=0.005)$, not having toothache or discomfort (OR 2.88, $\mathrm{P}=0.001)$, tooth brushing once or twice daily (OR 2.43, $\mathrm{P}=0.034$ ), and not consuming soft drinks (OR 1.96, $\mathrm{P}=0.027$ ) were significant predictors of routine dental visits.

Conclusion: The study found that higher education of mothers, daily tooth brushing, not having dental pain, and not consuming soft drinks were significantly associated with routine dental visits in this sample of female schoolchildren. Routine dental attendance may be used to improve oral hygiene and reduce dental pain and consumption of soft drinks in children. Keywords: dental attendance, access to oral care, soft drinks, toothache

\section{Introduction}

Oral health is an integral part of systemic health and oral diseases affect general health and wellbeing throughout life. ${ }^{1}$ Literature also indicates a robust relationship between periodontal diseases and systemic diseases ${ }^{2}$ and inflammatory mediators play an important role in this oral-systemic link. ${ }^{3,4}$ Dental attendance patterns reflect one's ability to access oral care services and can help prevent many dental diseases. ${ }^{1}$ Regular dental visits are important for the maintenance of optimal oral
Correspondence: Muhammad Ashraf Nazir

Tel +966543569615

Email manazir@iau.edu.sa 
health and improved quality of life and contribute to general health and wellbeing. Additionally, dental visiting patterns in childhood are associated with positive oral health outcomes and improved oral health-related quality of life in adulthood. ${ }^{5}$

A recent meta-analysis shows that dental visits are significantly associated with a reduced risk of periodontitis. ${ }^{6}$ Conversely, lack of dental visits is an indicator of unmet oral health needs. ${ }^{1}$ Irregular dental visits can contribute to the deposition of plaque and calculus in addition to poor toothbrushing. ${ }^{6}$ Evidence confirms that increased plaque accumulation corresponds with greater caries experience in children ${ }^{7}$ and lack of regular dental care can increase their risk of dental caries. ${ }^{1,8}$ Furthermore, children who break dental appointments are at increased risk of developing new carious lesions and having greater caries experience. ${ }^{9}$

Many sociodemographic factors, oral hygiene behaviors, and dietary habits affect patterns of dental visits in children. $^{10,11}$ A study of primary school children in Australia reported that age and insurance coverage were significantly associated with dental visits during the last one year. The study also reported an increased likelihood of biannual dental visits with the consumption of chocolate. $^{10}$ Education of parents is related to their oral health knowledge which can determine the frequency of their children's dental visits. ${ }^{12}$ Evidence shows that mothers' higher education is associated with routine/regular dental visits of their children. ${ }^{11}$ Other factors that affect dental care seeking behaviour include socioeconomic status, availability of time, behavioral beliefs, and costs of dental care. ${ }^{12-14}$ According to the Medical Expenditure Panel Survey in the U.S, the utilization of dental care increased in children from 2001 through 2010, however, factors such as age, gender, parent's education, income, and insurance could not explain this increase. $^{15}$

In the Eastern Province of Saudi Arabia, previous studies evaluated dental care utilization among teenage schoolchildren. ${ }^{15-17}$ Half the sample (51\%) of male school children (13-14 years) in Dammam visited the dentist during the past one year and dental pain was the most common reason for dental attendance. ${ }^{16}$ Another study reported routine dental attendance in $18.9 \%$ of male grade 10-12 schoolchildren in Dammam. ${ }^{17}$ Alhumaid et al observed routine dental check-ups in $14.4 \%$ of schoolchildren (6-12 years old) in the Eastern Province. ${ }^{18}$ A study from Riyadh, Saudi Arabia found dental attendance due to dental pain in $58 \%$ of $6-12$ years old children. ${ }^{19}$

Children are the most vulnerable group of the population who experience difficulties in accessing oral care services because they are dependent on parents/caregivers for their dental appointment and oral hygiene and dietary needs. ${ }^{14}$ Therefore, the investigation of dental care utilization and its associated factors in primary/elementary school children can help improve their access to oral care services and reduce the burden of oral diseases. However, there is a lack of data about the patterns of dental visits among young female children in Saudi Arabia. Therefore, the aim of the study was to evaluate patterns of dental visits in female school children in Dammam, Saudi Arabia. The study also investigated the factors associated with routine dental attendance.

\section{Materials and Methods}

This cross-sectional study included children from primary/ elementary female public schools in Dammam, Eastern Province, Saudi Arabia. The sample size was calculated for the study and sample size estimation included 1) estimated study population $(\approx 10,000), 2)$ anticipated frequency $(\mathrm{p}=50 \%), 3) \pm 4 \%$ confidence limit, and 4) design effect of 1 . These calculations generated a sample of 567 children. The Ministry of Education randomly selected four female schools in Dammam and an approximately equal number of participants from each school were included in the study. Among selected schools, the administrators approved the collection of data. The schoolchildren who were willing/assented to participate in the research and provided their parents' informed consent were eligible to participate in the study. Those with a systemic condition and without parental informed consent were excluded from the study. The informed consent contained the purpose and details of the study, information about voluntary participation, and privacy and confidentiality of data. The administration of an anonymous questionnaire ensured the privacy and confidentiality of study participants. Ethical approval (IRB 2020-02-068) was obtained from the Deanship of Scientific Research at Imam Abdulrahman Bin Faisal University, Dammam. The study was conducted in accordance with the Declaration of Helsinki.

The study used the World Health Organization's oral health questionnaire to assess dental visits, oral hygiene behaviors, dental problems, and dietary behaviors. ${ }^{20}$ The questionnaire used in the study can be divided in three 
sections. The first section included demographic information such as age, class year, parental education, and monthly family income. Questions about dental visits, oral hygiene behaviours, dietary practices were in the second section of the questionnaire. There were questions about the frequency and reasons for dental visits. The question about the frequency of dental visits inquired about dental attendance during the past 12 months, oncemore than four times per year, and never visiting the dentist. The reasons for dental visits included pain or trouble with teeth, gums or mouth, treatment/follow-up treatment, and routine check-ups of teeth/treatment. Oral hygiene behaviors assessment included frequency of tooth brushing (once or twice per day and week etc.) and use of toothpaste. Daily, weekly, monthly, and never consumption of soft drinks and biscuits, cakes, and creams were sought in the study. The last section of the questionnaire inquired participants about dental pain and dental problems. Information regarding toothache or feeling discomfort due to teeth during the past one year was obtained. Problems with teeth or mouth during the past one year included difficulty in biting hard food, difficulty in chewing, and not satisfied with the appearance of teeth. Clinical oral examination was performed to record decay in the first permanent molars. The World Health Organization's guidelines were used to record decay in the first permanent molar. Three calibrated dental interns performed clinical examination and inter-and intra-examiner reproducibility (Kappa statics $>80$ ) was achieved. Decay was examined using a disposable mouth mirror and a probe under adequate natural daylight in classrooms. ${ }^{20}$

The questionnaire was translated into the Arabic language using the forward translation method. ${ }^{21}$ The questionnaire was then pretested through a pilot study of 30 parents which helped evaluate the validity of the questionnaire, time required to complete it, and understanding and comprehension of questions by the respondents. The data of the pilot study were not included in the final analysis. The self-administered questionnaire was sent to the parents and those who wanted to voluntarily participate in the study returned the filled questionnaires.

The proportions and $95 \%$ confidence intervals of categorical variables (e.g., fathers' and mothers' education, family income, tooth brushing, etc.) were calculated. Bivariate analysis was performing using a chi-square test which assessed the association of independent variables (fathers' and mothers' education, family income, tooth brushing, consumption of soft drinks, toothache during the past one year, etc.) with the dependent variable (routine dental visits). The final logistic regression model (Forward LR) was created due to its superior predictive power. The final regression model was used to control for confounding factors in the study. SPSS software (IBM SPSS Statistics for Windows, version 22.0. Armonk, NY: IBM Corp) was used for statistical analysis. A p-value of $<$ 0.05 was considered statistically significant.

\section{Results}

The response rate of the study was $79.2 \%$ as 449 out of 567 parents returned completed questionnaires. The age of children ranged from 6 to 11 years with a mean age of $8.21 \pm 1.34$ years. More than half of the children had university educated parents and $75.3 \%$ belonged to the middle/high income group. Toothache or discomfort due to teeth in the last 12 months was experienced by $51.7 \%$ of children. Decay in the first molar teeth was found in $44.3 \%$ of children. The vast majority of children $(95.3 \%)$ consumed biscuits, cakes, cream several times a day to once a week and $42.8 \%$ consumed soft drinks. Tooth brushing once or twice daily $(73.9 \%)$ was common among children. (Table 1).

Most children (64.1\%) visited the dentist during the past one year, $22.1 \%$ performed no dental visit during the past one year, and $8.3 \%$ never visited the dentist. (Figure 1). Among children who visited the dentist, the pain or trouble with teeth, gums or mouth was the most common reason for dental visit $(39.10 \%, \mathrm{~N}=170)$, followed by routine dental check-up $(18.60 \%, \mathrm{~N}=81)$, and treatment/follow uptreatment (14.5\% N=63). (Figure 2).

The bivariate analysis shows the association of various factors with routine dental attendance (Table 2). Sociodemographic factors such as university education of mothers (odds ratio (OR) 4.24, $\mathrm{P}<0.001$ ) and of fathers (OR 2.56, $\mathrm{P}<0.001$ ), and middle/high family income (OR $2.82, \mathrm{P}=0.004)$ were significantly associated with routine dental attendance. Similarly, tooth brushing once or twice daily (OR 3.32, $\mathrm{P}=0.001$ ), not having decay in the first permanent molar (OR 2.01, $\mathrm{P}=0.007$ ), not having toothache or discomfort (OR 5.29, $\mathrm{P}<0.001$ ), and no consumption of soft drinks (OR 1.86, $\mathrm{P}=0.017$ ), and no consumption of biscuits, cakes, and cream (OR 2.99, $\mathrm{P}=0.014$ ) were significantly associated with routine dental attendance (Table 2).

In the multiple logistic regression analysis, statistically significant factors associated with routine dental visits included university education of mothers (OR 2.52, $\mathrm{P}=$ 0.005), not having toothache or discomfort due to teeth in 

Table I Demographic and Oral Health Information of
Schoolchildren

\begin{tabular}{|c|c|}
\hline Variables & Proportions $\left(95 \% \mathrm{Cl}^{*}\right)$ \\
\hline \multicolumn{2}{|l|}{ Class year } \\
\hline Grade $1-2$ & $49.2(42.1,52.6)$ \\
\hline Grade 3-4 & $50.8(47.4,57.9)$ \\
\hline \multicolumn{2}{|l|}{ Mother's Education } \\
\hline No/school education & $47.2(38.2,47.9)$ \\
\hline University education & $52.8(52.1,61.8)$ \\
\hline \multicolumn{2}{|l|}{ Father's Education } \\
\hline No/school education & $43.4(36.3,46.3)$ \\
\hline University education & $56.6(53.7,63.7)$ \\
\hline \multicolumn{2}{|l|}{ Monthly Family Income } \\
\hline Low income & $24.7(20.2,28.8)$ \\
\hline Middle/high income & $75.3(71.2,79.8)$ \\
\hline Dental insurance & $39.6(35.5,45.2)$ \\
\hline Toothache or discomfort teeth in last 12 months & $51.7(46.8,57.1)$ \\
\hline Tooth brushing (once or twice daily) & $73.9(70.4,79.5)$ \\
\hline Decay (dental caries) & $44.3(39.3,50.1)$ \\
\hline Not satisfied with the appearance of teeth & $30.6(25.5,34.6)$ \\
\hline Difficulty in biting hard food & $16.7(12.7,20.2)$ \\
\hline Difficulty in chewing food & $8.7(5.0,10.8)$ \\
\hline Consumed biscuits, cakes, cream & $95.3(93.9,97.8)$ \\
\hline Consumed soft drinks & $42.8(36.8,47.1)$ \\
\hline
\end{tabular}

Note: $* 95 \%$ confidence interval.

the last 12 months (OR 2.88, $\mathrm{P}=0.001)$, tooth brushing (OR 2.43, $\mathrm{P}=0.034)$, and not consuming soft drinks (OR $1.96, \mathrm{P}=0.027)$ (Table 3).

\section{Discussion}

The present study evaluated patterns of dental visits and predictors of routine dental attendance in female school children in Dammam, Saudi Arabia. The study showed that most female children visited dentists during the past one year and dental pain was the most common reason for dental visits. This finding is similar to many studies conducted locally and internationally. ${ }^{18,19,22-26}$ A review of epidemiological studies showed that there was a high prevalence of dental caries in children in Saudi Arabia. ${ }^{27}$ Children in the country also demonstrate poor oral hygiene, accumulation of dental plaque, and gingivitis. ${ }^{19,28}$ Dental caries and other dental diseases if left untreated can exacerbate oral problems and development of dental pain. Therefore, the high prevalence of oral diseases in children may explain the reasons behind increased dental visits due to dental pain in the present study. Furthermore, many parents (69.3\%) in Saudi Arabia prefer taking their children to the dentist in case of dental problems. ${ }^{29}$ The present study also indicated that $51.7 \%$ of children experienced toothache or discomfort due to teeth in the last 12 months and $44.3 \%$ had decay in the first permanent molars.

Routine dental visits provide many advantages which include: 1) early diagnosis and management of oral conditions, 2) oral health awareness of parents, 3) prevention of oral problems, and 4) improved oral health related quality of life. ${ }^{12}$ Despite these benefits, only $18.6 \%$ of children visited the dentist for routine dental check in the present study. A previous study from the Eastern province

\section{Frequency of dental visits}

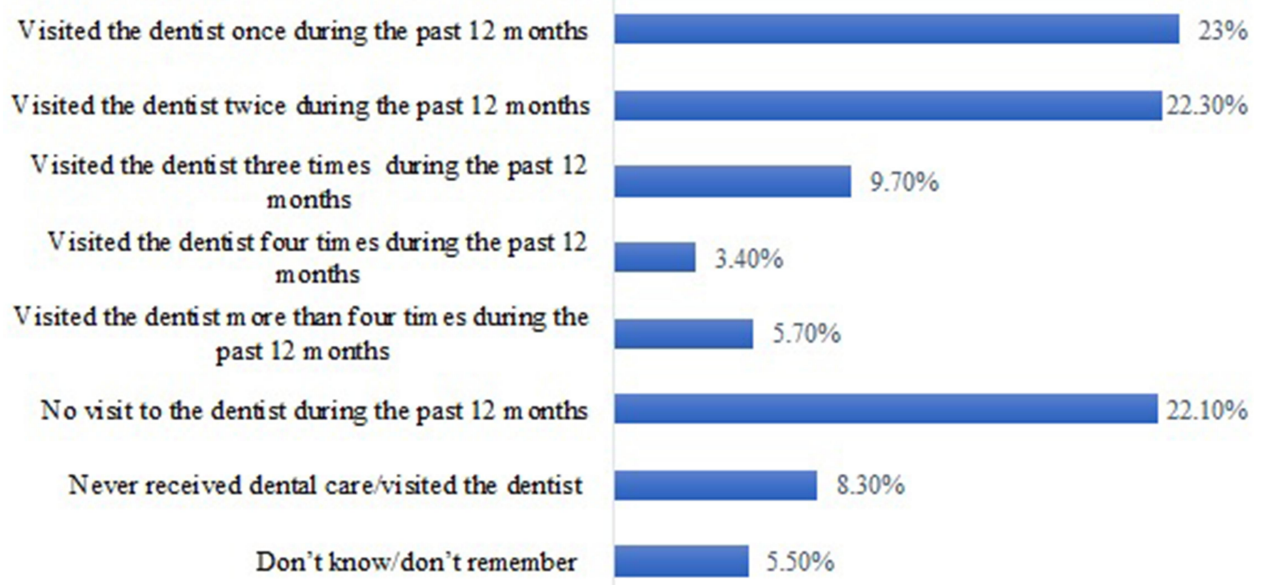

Figure I Frequency of dental visits among schoolchildren. 


\section{Reasons for dental visits}

Pain or trouble with teeth, gums or mouth

Treatment/follow-up treatment

Routine check-up of teeth/treatment

I don't know/don't remember

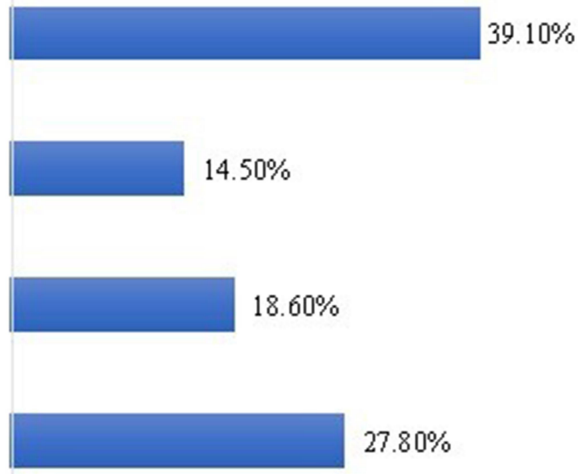

Figure 2 Reasons for dental visits among schoolchildren.

of Saudi Arabia found routine dental check-ups in 14.4\% of schoolchildren. ${ }^{18}$ Likewise, $11 \%$ of school children were shown to visit the dental office for regular checkups in Riyadh, Saudi Arabia. ${ }^{19}$ On the contrary, the National Survey of Children's Health reported preventive dental care visits in $72 \%$ of children in the U.S. ${ }^{30}$ Similarly, routine dental visits were performed by $81.7 \%$ of children in New Zealand. ${ }^{31}$ Greater prevalence of routine dental care can be related to increased education and oral health awareness among parents and the availability of preventive dental services in these developed countries.

The parents with higher educational attainment are more likely to care about oral hygiene behaviors and regular preventive dental check-ups of their children. ${ }^{32}$ A systemic review reported a significant correlation between the education level of parents and regular dental visits in children in 9 studies. ${ }^{33}$ Mothers in particular greatly influence the oral health of children because they spend more time with them and play a greater role in their upbringing and fostering their positive behaviours. Mothers with higher education levels have higher oral health knowledge, more positive attitude towards oral health, and improved oral health behaviors which positively influence the oral health status of their children. ${ }^{11}$ Highly educated mothers are known to play an important role in positive oral health behaviors of their children including routine dental visits. ${ }^{34}$ In the present study, after controlling for other variables in the final logistic regression model, higher education of mothers was significantly associated with routine dental visits of their children. The children of university educated mothers were
2.52 times more likely to perform routine dental visits than children of no/school educated mothers. This finding is in accordance with previous studies where higher education of mothers increased the likelihood of regular dental visits in their children. ${ }^{11,34}$

Routine dental visits provide opportunities for early detection of oral diseases and provision of dental care which can reduce dental problems including toothache. $^{12,35}$ The present study showed that children without toothache were 2.88 times more likely to perform routine dental visits than those with a toothache. The study provided clear evidence about the importance of routine dental visits in reducing dental pain. The literature shows that tooth brushing once or twice daily reduces plaque accumulation and thus decreases the risk of developing periodontal disease and dental caries in children. ${ }^{6,7}$ The present study showed that routine dental care was significantly associated with the increased likelihood $(\mathrm{OR}=2.43)$ of tooth brushing once or twice per day. The dentists may raise awareness about preventive oral behaviors during routine dental visits which may explain the reason for daily tooth brushing and no dental pain associated with routine dental attendance in our study.

Among preventive oral behaviors, routine dental visits are considered the third most important after oral hygiene and dietary practices. ${ }^{12}$ Parental knowledge is significantly correlated with oral hygiene and dietary practices of their children. ${ }^{29}$ It is documented that routine dental visits can increase oral health awareness among parents which has a significant positive influence on oral hygiene behaviors and dietary practices in their children. Societal pressure 
Table 2 Bivariate Analyses: Factors Associated with Routine Dental Attendance Among Participants

\begin{tabular}{|c|c|c|}
\hline Variables & $\begin{array}{l}\text { Unadjusted Odds } \\
\text { Ratio }(95 \% \mathrm{Cl})\end{array}$ & P-value \\
\hline $\begin{array}{l}\text { Class year } \\
\text { Grade I-2 } \\
\text { Grade 3-4 }\end{array}$ & $0.73(0.45,1.19)$ & 0.208 \\
\hline $\begin{array}{c}\text { Mother's Education } \\
\text { No/school education } \\
\text { University education }\end{array}$ & $4.24(2.39,7.52)$ & $<0.001$ \\
\hline $\begin{array}{c}\text { Father's Education } \\
\text { No/school education } \\
\text { University education }\end{array}$ & $2.56(1.50,4.39)$ & $<0.001$ \\
\hline $\begin{array}{l}\text { Monthly Family Income } \\
\text { Low income } \\
\text { Middle/high income }\end{array}$ & $2.82(1.35,5.88)$ & 0.004 \\
\hline Dental insurance & $1.18(0.71,1.95)$ & 0.519 \\
\hline $\begin{array}{l}\text { Toothache or discomfort in } \\
\text { last } 12 \text { months } \\
\text { Yes } \\
\text { No }\end{array}$ & $5.29(2.98,9.39)$ & $<0.001$ \\
\hline $\begin{array}{l}\text { Tooth brushing (once or } \\
\text { twice daily) }\end{array}$ & $3.32(1.61,6.88)$ & 0.001 \\
\hline Decay (dental caries) & $2.01(1.20,3.36)$ & 0.007 \\
\hline $\begin{array}{l}\text { Satisfied with the } \\
\text { appearance of teeths } \\
\text { No }\end{array}$ & $2.19(1.20,4.0)$ & 0.009 \\
\hline $\begin{array}{l}\text { Not having difficulty in } \\
\text { biting hard food }\end{array}$ & $20.2(2.77,147.6)$ & $<0.001$ \\
\hline $\begin{array}{l}\text { Not having difficulty in } \\
\text { chewing food }\end{array}$ & $9.24(\mathrm{I} .25,68.3 \mathrm{I})$ & 0.008 \\
\hline $\begin{array}{l}\text { No consumption of } \\
\text { biscuits, cakes, cream }\end{array}$ & $2.99(1.20,7.48)$ & 0.014 \\
\hline $\begin{array}{l}\text { No consumption of soft } \\
\text { drinks }\end{array}$ & $1.86(1.11,3.11)$ & 0.017 \\
\hline
\end{tabular}

and school requirements may increase parental awareness/ intention about the improved oral health of their children including routine dental visits. ${ }^{12,33}$ The present study showed that significantly low consumption of soft drinks was associated with routine dental attendance. Increased oral health knowledge because of routine dental visits and high education levels of parents may account for reduced consumption of soft drinks in our study. This study sheds light on the importance of regular dental attendance in
Table 3 Final Model Logistic Regression (Forward LR): Factors Associated with Routine Dental Attendance Among Participants

\begin{tabular}{|l|c|c|}
\hline Variables & $\begin{array}{l}\text { Adjusted Odds } \\
\text { Ratio (95\% Cl) }\end{array}$ & P-value \\
\hline $\begin{array}{l}\text { Mother's Education } \\
\text { No/school education } \\
\text { University education }\end{array}$ & $2.52(1.32,4.82)$ & 0.005 \\
\hline $\begin{array}{l}\text { Toothache or discomfort in } \\
\text { last I2 months } \\
\text { Yes } \\
\text { No }\end{array}$ & $2.88(\mathrm{I.54}, 5.38)$ & $0.00 \mathrm{I}$ \\
\hline $\begin{array}{l}\text { Tooth brushing (once or } \\
\text { twice daily) }\end{array}$ & $2.43(\mathrm{I} .07,5.50)$ & 0.034 \\
\hline $\begin{array}{l}\text { No consumption of soft } \\
\text { drinks }\end{array}$ & $1.96(\mathrm{I.08,3.55)}$ & 0.027 \\
\hline
\end{tabular}

reducing fermentable carbohydrates which have detrimental effects on both caries and periodontal disease, the most common oral conditions affecting billions of people around the word. ${ }^{36,37}$

The literature indicates the lack of parents' knowledge about the oral hygiene behaviours and risk factors of oral health among their children. A recent study reported that only $24 \%$ of parents were aware of the transmission of cariogenic bacteria from mothers to their children and 57\% reported starting toothbrushing when their children were between the age of 2-3 years. ${ }^{38}$ Therefore, there is a need for raising parents' awareness of oral health for the optimal health of their children. In addition, preventive school programs can play an important role in improving the oral health of children. ${ }^{39}$

Regular dental attendance provides preventive dental care that can lead to fewer oral diseases, reduced dental treatment needs, and fewer negative oral outcomes. Since young children are predisposed to great oral health inequalities and the high burden of oral diseases for them, their families, and healthcare systems. Therefore, interdisciplinary measures are needed to enhance awareness, availability, and accessibility of routine dental care for children. The study adds useful information on the current literature regarding dental visits in female schoolchildren.

The investigation of associations of dental problems and dietary behaviors with routine dental care filled the knowledge gap on dental attendance among children. However, due to the limitations of the cross-sectional study design, cause-effect relationships should not be 
inferred. Hence, it is not possible to determine the temporal relationship between different factors and routine dental attendance in the present study. For instance, it cannot be inferred that routine dental attendance actually reduced toothache or discomfort, decreased soft drinks consumption, and improved tooth brushing in our sample of children. Decay in the first permanent molars was assessed in the present study because these teeth are most commonly affected with caries and caries in the first permanent molars which is significantly associated with caries in second molars, premolars, and incisors. ${ }^{40}$ However, caries evaluation in the first permanent molar may underestimate the extent and severity of caries in these children. Previous studies reported a high prevalence of orthodontic treatment needs in children, ${ }^{41,42}$ and emphasized the important role of pediatricians in oral health promotion of children. ${ }^{41}$ The study did not include information about malocclusion and physicians' awareness of early dental visits for children. Despite these limitations, the study findings provide the impetus for further investigation of these and additional factors by using a cohort study design. The study results should not be generalized to male primary/elementary school children in Dammam.

\section{Conclusions}

The study found that dental pain was the most common reason for dental visits in this sample of children. There was a low prevalence of routine dental attendance among participants. Higher education of mothers, daily tooth brushing, not having toothache, and not consuming soft drinks were significantly associated with routine dental visits. Preventive initiatives aimed at encouraging routine dental visits should be implemented to reduce oral health inequalities in schoolchildren.

\section{Acknowledgments}

The authors are grateful to female dental interns for their great help in data collection.

\section{Disclosure}

The authors report no conflicts of interest in this work.

\section{References}

1. Rockville M. Oral Health in America: A Report of the Surgeon General. US Department of Health and Human Services of Dental and Craniofacial of Health. National Institute of Health; 2000.
2. Nazir MA. Prevalence of periodontal disease, its association with systemic diseases and prevention. Int J Health Sci. 2017;11(2):72-80.

3. Matarese G, Isola G, Anastasi GP, et al. Immunohistochemical analysis of TGF- $\beta 1$ and VEGF in gingival and periodontal tissues: a role of these biomarkers in the pathogenesis of scleroderma and periodontal disease. Int J Mol Med. 2012;30(3):502-508. doi:10.3892/ ijmm.2012.1024

4. Isola G, Polizzi A, Alibrandi A, Williams RC, Leonardi R. Independent impact of periodontitis and cardiovascular disease on elevated soluble urokinase-type plasminogen activator receptor (suPAR) levels. J Periodontol. 2020. doi:10.1002/JPER.20-0242

5. Crocombe LA, Broadbent JM, Thomson WM, Brennan DS, Poulton R. Impact of dental visiting trajectory patterns on clinical oral health and oral health-related quality of life. $J$ Public Health Dent. 2012;72(1):36-44. doi:10.1111/j.1752-7325.2011.00281.x

6. Lertpimonchai A, Rattanasiri S, Arj-Ong Vallibhakara S, Attia J, Thakkinstian A. The association between oral hygiene and periodontitis: a systematic review and meta-analysis. Int Dent J. 2017;67 (6):332-343. doi:10.1111/idj.12317

7. Gopinath VK, Rahman B, Awad MA. Assessment of gingival health among school children in Sharjah, United Arab Emirates. Eur J Dent. 2015;9(1):36-40. doi:10.4103/1305-7456.149636

8. Tinanoff $\mathrm{N}$ State surveys of oral health needs and dental care access for children: summary of 15 state reports: children's dental health project; 1998.

9. Wang NJ, Aspelund GO. Children who break dental appointments. Eur Arch Paediatr Dent. 2009;10(1):11-14. doi:10.1007/ BF03262660

10. John JR, Mannan H, Nargundkar S, et al. Predictors of dental visits among primary school children in the rural Australian community of Lithgow. BMC Health Serv Res. 2017;17(1):264. doi:10.1186/ s12913-017-2232-1

11. Nourijelyani K, Yekaninejad MS, Eshraghian MR, et al. The influence of mothers' lifestyle and health behavior on their children: an exploration for oral health. Iran Red Crescent Med J. 2014;16(2): e16051. doi:10.5812/ircmj.16051

12. Badri P, Saltaji H, Flores-Mir C, Amin M. Factors affecting children's adherence to regular dental attendance: a systematic review. $J$ Am Dent Assoc. 2014;145(8):817-828. doi:10.14219/jada.2014.49

13. Amin M, ElSalhy M. Factors affecting dental attendance of children of new immigrant parents: a Cross-Sectional Study. J Immigr Minor Health. 2017;19(6):1351-1361. doi:10.1007/s10903-016-0441-z

14. Bersell $\mathrm{CH}$. Access to oral health care: a national crisis and call for reform. J Dent Hyg. 2017;91(1):6-14.

15. Vujicic M, Nasseh K. A decade in dental care utilization among adults and children (2001-2010). Health Serv Res. 2014;49 (2):460-480. doi:10.1111/1475-6773.12130

16. Nazir MA. Patterns of dental visits and their predictors among male adolescents. Dent Med Probl. 2018;55(2):185-190. doi:10.17219/ dmp $/ 87023$

17. Nazir MA. Predictors of routine dental check-up among male adolescents in Saudi Arabia. Acta Stomatol Croat. 2019;53(3):255-263. doi:10.15644/asc53/3/7

18. AlHumaid J, El Tantawi M, AlAgl A, et al. Dental visit patterns and oral health outcomes in Saudi children. Saudi J Med Med Sci. 2018;6 (2):89-94. doi:10.4103/sjmms.sjmms_103_17

19. Kannan SP, Alfahaid SF, Alharbi AS, et al. Oral hygiene behavior of school children in Saudi Arabia: a descriptive cross-sectional survey. Int J Clin Pediatr Dent. 2020;13(1):66-71. doi:10.5005/jp-journals -10005-1710

20. World Health Organization. Oral Health Surveys: Basic Methods. 5th ed. 2013.

21. Tsang S, Royse CF, Terkawi AS. Guidelines for developing, translating, and validating a questionnaire in perioperative and pain medicine. Saudi J Anaesth. 2017;11(Suppl 1):S80-S89. doi:10.4103/sja.SJA_203_17 
22. Ahmed SM, Soliman AM, Elmagrabi NM, Sayed S. Oral health knowledge, attitude and practice among primary school children in rural areas of Assiut governorate. Egypt $J$ Community Med. 2015;33:4.

23. Murshid EZ. Children's ages and reasons for receiving their first dental visit in a Saudi community. Saudi Dent J. 2016;28 (3):142-147. doi:10.1016/j.sdentj.2015.12.003

24. Al-Kheraif AA, Al-Bejadi SA. Oral hygiene awareness among female Saudi school children. Saudi Med J. 2008;29(9):1332-1336.

25. Rajab LD, Petersen PE, Bakaeen G, Hamdan MA. Oral health behaviour of schoolchildren and parents in Jordan. Int J Paediatr Dent. 2002;12(3):168-176. doi:10.1046/j.1365-263X.2002.00359.x

26. Punitha V, Sivaprakasam P. Oral hygiene status, knowledge, attitude and practices of oral health among rural children of Kanchipuram district. Indian J Multidiscip Dent. 2011;1:2.

27. Al Agili DE. A systematic review of population-based dental caries studies among children in Saudi Arabia. Saudi Dent J. 2013;25 (1):3-11. doi:10.1016/j.sdentj.2012.10.002

28. AlGhamdi AS, Almarghlani AA, Alyafi RA, Kayal RA, Al-Zahrani MS. Gingival health and oral hygiene practices among high school children in Saudi Arabia. Ann Saudi Med. 2020;40(2):126-135. doi:10.5144/0256-4947.2020.126

29. Kotha SB, Alabdulaali RA, Dahy WT, et al. The influence of oral health knowledge on parental practices among the Saudi parents of children aged 2-6 years in Riyadh City, Saudi Arabia. J Int Soc Prev Community Dent. 2018;8(6):565-571. doi:10.4103/jispcd.JISPCD_341_18

30. Lewis CW, Johnston BD, Linsenmeyar KA, Williams A, Mouradian W. Preventive dental care for children in the United States: a national perspective. Pediatrics. 2007;119(3):e544-e553. doi:10.1542/peds.2006-1958

31. Thomson WM, Williams SM, Broadbent JM, Poulton R, Locker D. Long-term dental visiting patterns and adult oral health. J Dent Res. 2010;89(3):307-311. doi:10.1177/0022034509356779

32. Saldūnaitė K, Bendoraitienė EA, Slabšinskienė E, et al. The role of parental education and socioeconomic status in dental caries prevention among Lithuanian children. Medicina. 2014;50(3):156-161. doi:10.1016/j.medici.2014.07.003
33. Naidu R, Nunn J, Forde M. Oral healthcare of preschool children in Trinidad: a qualitative study of parents and caregivers. BMC Oral Health. 2012;12(1):27. doi:10.1186/1472-6831-12-27

34. Camargo MB, Barros AJ, Frazão P, et al. Predictors of dental visits for routine check-ups and for the resolution of problems among preschool children. Rev Saude Publica. 2012;46(1):87-97.

35. Langevin SM, Michaud DS, Eliot M, et al. Regular dental visits are associated with earlier stage at diagnosis for oral and pharyngeal cancer. Cancer Causes Control. 2012;23(11):1821-1829.

36. Nyvad B, Takahashi N. Integrated hypothesis of dental caries and periodontal diseases. J Oral Microbiol. 2020;12(1):1710953. doi:10.1080/20002297.2019.1710953

37. Frencken JE, Sharma P, Stenhouse L, et al. Global epidemiology of dental caries and severe periodontitis - a comprehensive review. J Clin Periodontol. 2017;44(Suppl 18):S94-S105. doi:10.1111/ jcpe. 12677

38. Calcagnile F, Pietrunti D, Pranno N, et al. Oral health knowledge in pre-school children: a survey among parents in central Italy. J Clin Exp Dent. 2019;11(4):e327-e33. doi:10.4317/jced.55378

39. Vozza I, Capasso F, Calcagnile F, et al. School-age dental screening: oral health and eating habits. Clin Ter. 2019;170(1):e36-e40. doi:10.7417/CT.2019.2105

40. Nazir MA, Bakhurji E, Gaffar BO, Al-Ansari A, Al-Khalifa KS. First permanent molar caries and its association with carious lesions in other permanent teeth. J Clin Diagn Res. 2019;13:1.

41. Luzzi V, Ierardo G, Corridore D, et al. Evaluation of the orthodontic treatment need in a paediatric sample from Southern Italy and its importance among paediatricians for improving oral health in pediatric dentistry. J Clin Exp Dent. 2017;9(8):e995-e1001. doi:10.4317/ jced.54005

42. Al-Qurashi H, Al-Farea M, Alshamrani A, Almasoud NN, Nazir A. Orthodontic treatment needs and association between malocclusion and oral hygiene behaviors. Paki Oral Dent J. 2018;38:1.
Clinical, Cosmetic and Investigational Dentistry

\section{Publish your work in this journal}

Clinical, Cosmetic and Investigational Dentistry is an international, peer-reviewed, open access, online journal focusing on the latest clinical and experimental research in dentistry with specific emphasis on cosmetic interventions. Innovative developments in dental materials, techniques and devices that improve outcomes and patient satisfaction and preference will be highlighted. The manuscript management system is completely online and includes a very quick and fair peer-review system, which is all easy to use. Visit http://www.dovepress.com/testimonials.php to read real quotes from published authors. 